\title{
Análisis Sobre el Control Judicial de los Decretos Reglamentarios del Salario de los Fiscales
}

\section{Analysis on the judicial control on the mandatory decrees of the salary for prosecutors}

\begin{abstract}
JOHANN WOLFGANG PATIÑO CARDENAS
Abogado de la Facultad de Derecho de la Universidad Santo Tomás, Bogotá, actualmente culminando el programa de Especialización en Derecho Administrativo de la Universidad Santo Tomás. Correo Electrónico. jwolpc@hotmail.com

Attorney at law from the law faculty of the Santo Tomas University, Bogota, currently finishing the specialization in Administrative Law at the Santo Tomas

University.E-mail: jwolpc@hotmail.com
\end{abstract}

Fecha de recepción: 17 de febrero de 2011 Fecha de evaluación: 20 de mayo de 2011 Fecha de aprobación: 30 de mayo de 2011

Resumen: El control judicial de los Decretos expedidos por el Presidente de la República, en ejercicio de las funciones otorgadas por la Constitución y la ley 4 de 1992, por el cual estableció, entre otros, el régimen salarial y prestacional de la Fiscalía General de la Nación, debe responder a los nuevos criterios de aceptabilidad general y de argumentación jurídica, con el fin de que la traducción del ordenamiento jurídico Colombiano dentro del Estado Social de Derecho, se materialice, cumpliendo así con la meta de que "todo sea tal como el 
ordenamiento dice que debe ser, pese al desconocimiento o negación que en la práctica se haga de él."

Palabras Claves: Argumentación Jurídica, Acto Administrativo, Ciencia Jurídica, Consejo de Estado, Control, Cosa Juzgada, Decreto, Estado Social de Derecho, Ex Tunc, Función Administrativa, Función Judicial, Juez, Jurisprudencia, Legalidad, Nulidad, Obiter Dictum, Proyecto de Ley, Ratio Decidendi, Remuneración del Servidor Público.

Abstract: The judicial control of the decrees issued by the President of the Republic, in exercising the functions granted by the Constitution and the act 4 of 1992, by which established, among others, the regime wage and provider of the Físcalía General de la Nación, it must respond to the new criteria of general acceptability and legal argument, with the end of the translation of Colombian legal system within the Social State of Law, to materialize, thus complying with the goal of "everything is as management says it must be, despite the ignorance or denial that in practice is make him"

Key Words: Administrative Act, Administrative Function, Control, Consejo de Estado, Decree, Ex Tunc, Judge, Judicial Function, Jurisprudence, Legal 
Argument, Legal Science, Obiter Dictum, Project of Law, The Social State of Law, Res Judicata, Remuneration of the Public Servant

Tipo de Artículo: Reflexión Académica

\section{INTRODUCCIÓN}

Colombia es un Estado Social de Derecho, es social en tanto que busca defender los valores, principios, derechos y garantías que el sistema jurídico tiene como fin proporcionar, y, también es uno de derecho, puesto que busca materializar el principio de legalidad, la separación de poderes y el sometimiento a las normas.

El que todo sea tal como el ordenamiento dice que debe ser, pese al desconocimiento o negación que en la práctica se haga de él, es el fin o ideal que persigue nuestra sociedad. Incluso, cuando ello no es así es necesario que se dé una corrección.

Por esa razón, el tópico de la disertación es el control judicial de los decretos expedidos por el Presidente de la República, qué como suprema autoridad administrativa y en ejercicio de las funciones otorgadas por la Constitución y la ley 4 de 1992, estableció, entre otros, el régimen salarial y prestacional de la Fiscalía General de la Nación. 
El escrito pretende, de un lado, reflejar la materialización del Estado Social de Derecho, positivo y finalista, y de otro, dar respuesta a la problemática que inició esta disertación, cual era establecer si: ¿De acuerdo con la concepción del Estado Social de Derecho como fórmula política (un estado positivo y finalista), las decisiones adoptadas por la Jurisdicción Contencioso Administrativo frente a la prima especial sin carácter salarial prevista para la Fiscalía General de la Nación en los Decretos Reglamentarios del artículo 14 de la Ley 4 de 1992, realizan una materialización efectiva del ordenamiento jurídico colombiano?

En ese orden de ideas, la primera parte del escrito establecerá que la necesidad de realizar el análisis desde la perspectiva de la argumentación jurídica, con el objeto de que la ciencia jurídica cumpla con el fin de que todo sea tal como el ordenamiento dice que debe ser, pese al desconocimiento o negación que en la práctica se haga de él, y a su vez posea por si misma el elemento de la corrección, acto seguido, se expondrán algunos mínimos ideológicos sobre la administración, posteriormente, se esbozara el entorno histórico del tópico de análisis y se continuara con el estudio de dos de las sentencia proferidas sobre el tema, para finalmente terminar con algunas conclusiones.

\section{Aceptabilidad general como método correctivo en de la ciencia jurídica}

Esta primera unidad, intenta establecer un parámetro para identificar como se debe entender la siguiente frase: la función del derecho es que todo sea tal como 
el ordenamiento dice que debe ser, pese al desconocimiento o negación que en la práctica se haga de él.

Esto, en tanto que si bien la valoración del sistema jurídico sufrió una especie de transición o revaloración, porque el centro de gravedad del derecho, ha dejado de ser exclusivamente la ley y se ha trasladado hacía quien la aplica, ello no puede traducirse en que el derecho es lo que el juez dice.

Colombia como Estado Social de Derecho, quiere satisfacer, tanto la legalidad, como la eficacia y las consecuencias sociales, lo que podría identificarse como una simbiosis de las escuelas de derecho, en tanto que el mismo, debe poseer una legalidad en sus normas, y estas a su turno deben ser justas, de forma que siempre se debe cumplir con el fin social para el cual fueron constituidas, pero bajo las formas que el mismo sistema prevé.

Las tesis de la aceptabilidad general, o de la argumentación jurídica, permiten satisfacer plenamente los requisitos enunciados, en tanto predican que si bien no es posible encontrar una solución única a los problemas del derecho, esta es susceptible de ser alcanzada en una mayor medida, siempre que las decisiones jurídicas adoptadas, provengan de una conclusión racional.

Mora (2006) expone, que la teoría tradicional por la cual se nos decía que sí la norma es clara, ésta se aplica simplemente, sin necesidad de interpretarla, se 
desdibuja, y por el contrario, se debe aceptar que los textos legales exigen ser interpretados, para deducir así la norma jurídica, porque suponen de parte del intérprete una comprensión de su propio sentido. La norma jurídica, es un fenómeno del lenguaje. Los textos legales son mandatos solamente como actos de comunicación.

Desde este punto de vista, siendo que el texto jurídico se puede diferenciar de la norma jurídica, y ésta última sólo aparece en cada uno de los intérpretes, puede dilucidarse que es posible encontrar múltiples normas jurídicas de un solo texto legal, lo que implica que sea complejo traducirlo y por tanto lograr que todo sea tal como el ordenamiento dice que debe ser.

Debe tenerse presente, que dentro de un Estado como el nuestro, el juez no puede resolver las situaciones jurídicas puestas a su conocimiento basado únicamente en su voluntad y con olvido del ordenamiento jurídico escrito, fundamentándose en que esa es la norma jurídica que logra abstraer.

Es este último punto, el que aleja a las escuelas del derecho, y por supuesto, el que impide consagrar al realismo jurídico como la forma de interpretación jurídica adecuada, ya que, la voluntariedad del juez se hace a un lado, para dar paso a las mencionadas tesis de la aceptabilidad general, o de la argumentación jurídica, por las que, entre otras, se pretende volver univoca la interpretación normativa de los textos legales, y salvaguardar así la unidad interpretativa del mismo. 
Sí tomáramos una posición que establezca que es imposible encontrar en el texto legal una norma jurídica que goce de aceptabilidad general, es decir, una forma de interpretación, el que todo sea tal como el ordenamiento dice que debe ser, pese al desconocimiento o negación que en la práctica se haga de él resultaría en un imposible.

"El texto legal, como parte del derecho, es una noción que debe repetirse consecuencialmente desde su concepción en la norma superior hasta su puesta en práctica en el caso concreto", Marín (2007).

Atienza, M. (1990), expone que: la teoría estándar de la argumentación jurídica estudia los aspectos normativos de la justificación o fundamentación de las decisiones tomadas por órganos judiciales.

Siendo ello así, lo primero que habría de indagarse, es qué puede constituir una justificación de la decisión, a lo cual, se debe responderse que la única justificación posible yace en el cumplimiento de la normatividad, es decir, tanto en lo procedimental como en lo sustancial, lo que implica también el logro de los fines previstos por la Constitución.

Para el efecto, Villamil, E. (2004) expone que: 
La justificación y motivación de las decisiones judiciales, obedece entonces a la necesidad de evitar la arbitrariedad de los jueces: ellos en sus fallos deben exponer las disposiciones legales y las razones de justicia o equidad que constituyen los fundamentos de la decisión, así como la apreciación que hacen de las pruebas aducidas y de los alegatos presentados por las partes.

Un ordenamiento jurídico evolucionado sólo considera admisibles aquellas decisiones fundamentadas en juicios, criterios o parámetros claramente identificables que puedan ser examinados desde una perspectiva externa a la decisión misma. Supone la elección entre diversas alternativas; ello implica que es posible construir varias decisiones y que aquella con pretensión de erigirse en la decisión judicial es apenas una dentro de un repertorio de soluciones posibles que emulan por ganar la adhesión del autor.

Todo lo enunciado, quiere significar que al entender que el derecho tiene como meta cumplir determinado fin, en el caso de Colombia, los previstos por el Estado Social de Derecho, y por otra parte, que las soluciones a los casos concretos se sustentan en argumentos, susceptibles de ir mejorando para generar mayor asimilación social, siguiendo a Máynes (2002): “la expresión derecho correcto es en el fondo un pleonasmo. Puede haber leyes incorrectas, pero no "derecho 
incorrecto". En el concepto de derecho está necesariamente contenido el elemento de la corrección."

Vale la pena por tanto, poner de presente siguiendo a Máynes (2002), que si admitimos que todo orden jurídico tiene la misión de realizar valores sociales, justicia, seguridad, bien común, las prescripciones legales, incluyendo dentro de estas las sentencias judiciales, que lejos de realizar esos valores, abiertamente los vulnera, es posible que la conciencia jurídica se niegue a admitirlas como verdadero derecho. Por lo que, solamente queda una posibilidad:

[E]l derecho intrínsecamente valido es el contenido en las sentencias de los jueces, cuya tarea, constituirá una "gradual actualización o concretización", no sólo de las leyes, sino de los principios generales que necesariamente integran el trasfondo axiológico de la obra del legislador.

En dicho sentido: Derecho valido es el contenido en las sentencias argumentadas que den fe, como se vio con Villamil (2004), de las disposiciones legales en las que se sustentan y las razones de justicia o equidad que constituyen los fundamentos de la decisión. A su vez, siguiendo a Marín (2007.), a efectos de la valoración de la actividad judicial debe tomarse en consideración que estas están sujetas al cumplimiento de unos fines. Razón por la cual, lo más importante es cuál de las formas de fallo condensan en mayoría los fines postulados por la sociedad, que en últimas traducirán en la norma jurídica de aceptabilidad general. 


\section{Aspectos generales de la administración}

La capacidad de la administración como órgano del Estado que ejecuta y lleva a buen término las disposiciones legales, se encuentra sujeta, en términos generales, a las disposiciones previstas en los artículos 4, 6, 121 y 122 de la Constitución, junto con el artículo 5 de la ley 489 de 1998 y el artículo 2 del Código Contencioso Administrativo. La siguiente idea expuesta por Marín (2007), reproduce en cierta medida dichas consecuencias:

No es posible la existencia de un acto sin la potestad previa, ni la de ésta si no ha sido consignada expresamente en el ordenamiento -, su extensióndeterminada o determinable-, las formas y procedimientos de imperativa observancia para su expedición y la competencia del órgano que la realiza, además del contenido de la decisión misma en algunos casos.

En la clasificación de los actos administrativos, se encuentran e interesan aquí, algunos decretos que el Presidente de la República puede expedir, a los que Berrocal (2009) denomina "reglamentarios especiales", y con los que se quiere identificar a los decretos reglamentarios de leyes marco, al respecto pueden ser consultadas, las sentencias 612 IJ de 23 de julio de 1996, Consejero Ponente: Juan Alberto Polo Figueroa; y Al- 054 y 6584 Acumulados de 31 de julio de 2003, Consejero Ponente: Gabriel Eduardo Mendoza Martelo. 
Estos decretos, regulan materias señaladas por la Constitución, pero con sujeción a objetivos y criterios señalados en la ley, materias que son principalmente las previstas en el numeral 19 del artículo 150 de la Constitución, facultades entre las que se encuentra la de fijar el régimen salarial y prestacional de los empleados públicos, de los miembros del Congreso Nacional y de la Fuerza Pública, cuya ley marco es la $4^{\mathrm{a}}$ de 1992.

Para un mayor entendimiento de las facultades a las que se hace referencia, pueden ser consultadas, entre otras, la sentencias de la Corte Constitucional: C089 A de 3 de marzo de 1994, Magistrado Ponente: Vladimiro Naranjo Mesa; C668 de 16 de agosto de 2006, Magistrado Ponente: Jaime Araujo Rentería; y, C624 de 14 de agosto de 2007, Magistrado Ponente: Jaime Córdoba Triviño: por las que se establece, entre otras cosas, que la función de crear la parte "estática y permanente" de la administración pública corresponde al Congreso, mientras que el Gobierno se debe ocupar de la parte "dinámica" y cambiante de la misma, de acuerdo con los criterios generales que establezca la ley y las necesidades políticas y económicas del momento.

Ahora bien, los actos administrativos poseen unas causales de anulación. Vidal (2004) expone las causales así:

Violación de la ley: transgresión de toda norma de derecho cuyo respeto se imponía al autor del acto. [...] ¿en qué consiste la violación de la ley? En su 
violación flagrante, primeramente, cuando el acto contradice de manera evidente la norma superior. Hay violación de la ley cuando se aplaza sin motivo el cumplimiento de una norma o, lo que constituir la hipótesis más frecuente, la falsa interpretación y la equivocada aplicación.

Incompetencia: en obedecimiento al principio de la separación de los poderes y para garantía de los ciudadanos, la Constitución y las leyes reparten entre los distintos funcionarios las competencias. Por consiguiente, si una providencia determinada o un acto cualquiera es tomado por un funcionario distinto de aquel investido por la ley de poder para dictarlo, se viola la ley, y el acto es anulable.

Vicios de formas: la ley organiza un ritual que debe seguirse para dictar determinado acto. Cuando se saltan las instancias contempladas en la ley, cuando no se procede a las consultas que ella ordena, cuando no se cumple todo el procedimiento instituido, el acto es anulable por vicios de forma.

Falta de motivos o error en los motivos: [...] La medida puede ser ilegal si no la justifican los hechos que la provocaron. El juez entra a estudiar los hechos para ver si el motivo invocado se ha realizado, porque la legalidad del acto se funda en la realidad de los hechos invocados. [...] Resulta 
anulable cuando el funcionario ha incurrido en un error de hecho o de derecho sobre los motivos.

Desvió o desviación de poder: el móvil a diferencia del anterior, es el deseo que ha inspirado al autor, el fin que quiere lograr al producir ese acto. En ese sentido, hay desvió de poder cuando se emplea una facultad otorgada por la ley con un fin distinto del que la ley quería al otorgarla. Entonces es preciso buscar la intención que tuvo la ley al crear una competencia y el fin que ha querido el funcionario al dictar el acto.

Estas causales, se alegan ante el juez contencioso administrativo, de acuerdo con las reglas de competencia previstas en los artículos 128 a 134E del Código Contencioso Administrativo, mediante el ejercicio de las acciones de nulidad, y nulidad y restablecimiento del derecho, artículo 84 y 85 ibídem, dependiendo de si el acto administrativo a demandar es de contenido general o particular.

Los efectos de la anulación de los actos administrativos, se pueden apreciar en el artículo 175 del Código Contencioso administrativo, lugar en el que se dispone que la sentencia que declare la nulidad produce un efecto "erga omnes", es decir general, mientras que, en el caso de la nulidad y restablecimiento del derecho, dicha nulidad sólo aprovecha a quien hubiere intervenido en el proceso y obtenido una declaración a su favor. 
Vidal (2004), expone que: en la doctrina francesa se enseña que la anulación hace desaparecer el acto absolutamente, tiene efecto erga omens y es, además, prácticamente retroactiva: se considera el acto como si no se hubiera dictado jamás. La sentencia de nulidad actúa retroactivamente, ex tunc, por lo que una vez declarada la nulidad, sus efectos se retrotraen a la fecha del acto anulado. De requerirse una mayor amplitud sobre el entendimiento jurisprudencial de las acciones y sus distintos efectos pueden ser revisadas las sentencias del Consejo de Estado 9899 de 18 de abril de 1996, Consejero Ponente Carlos Betancur Jaramillo y IJ 030 de 4 de marzo de 2003, Consejero Ponente Manuel Santiago Urueta Ayola.

Valga aclarar que, bien sea como consecuencia de la suspensión provisional del acto administrativo, artículos 238 de la Constitución y 152 y ss. Del Código Contencioso Administrativo, o como resultado de la nulidad declarada por el juez, de acuerdo con lo dispuesto en el artículo 158 ibídem, existe prohibición expresa para reproducirlo si se conserva en esencia la misma disposición, a menos que con posterioridad hayan desaparecido los fundamentos legales de esa suspensión o anulación.

Cabe agregar, que en caso de que se reproduzca el acto nulo o suspendido, el Código Contencioso Administrativo, juzga como causal de mala conducta dicho proceder en el artículo 76, la cual además da lugar a la responsabilidad prevista 
en el artículo 77, la que debe entenderse ligada a la señalada en el artículo 90 de la Constitución.

\section{Historia del tópico de análisis}

El tópico de análisis de la presente disertación, presenta el siguiente desarrollo.

La Constitución Política de 1991, estatuyó en los artículos 249 a 253 lo relacionado con la creación de la Fiscalía General de la Nación. Así mismo, el constituyente determinó en los artículos transitorios 5, 10 y 11 ibídem, que el Presidente de la República, antes de que fuera instalado el Congreso que se elegiría el 27 de octubre de 1991, expediría las normas para organizar al ente en mención, mediante la expedición de decretos que tendrían fuerza de ley.

Dentro del término previsto, ya que el Congreso fue instalado el 12 de diciembre del mismo año, el Presidente expidió la norma que organizó a la Fiscalía General de la Nación, Decreto 2699 de 30 de noviembre de 1991. Esta norma dispuso que la entidad formaba parte de la Rama Judicial, artículo 1 ibídem, y determinó una escala de salarios, artículo 54 ibídem, para los empleados que se vincularan por primera vez y para que aquellos, que desempeñando sus funciones en la Rama

Judicial y que en virtud del decreto quedaron dentro de la planta de personal de la 
Fiscalía quisieran aceptarlo, parágrafo 3 del artículo 64, opción que debían ejercer dentro de los seis meses siguientes, es decir, hasta el 30 de mayo de 1992.

En este punto, es claro que a partir del 30 de noviembre de 1991, la Fiscalía General de la Nación, tenía dos tipos de remuneración para los Empleados Públicos de la entidad, una prevista en el artículo 54, y otra, para las personas que no aceptaron el nuevo régimen salarial y se quedaron con el que les venía siendo aplicado.

La Constitución, también previó que a iniciativa del Gobierno, el Congreso expediría, entre otras, las normas generales, señalando en ellas los objetivos y criterios a los cuales debe sujetarse el Gobierno para fijar el régimen salarial y prestacional de los Empleados Públicos, de los miembros del Congreso Nacional y la Fuerza Pública. En este sentido, el Exviceministro de Hacienda y Crédito Público Hector Cadena Clavijo, junto con el Exministro de Trabajo y Seguridad Social Francisco Posada de la Peña, presentaron el 19 de diciembre de 1991 al Senado de la republica el Proyecto de ley número 32 de 1991, con el fin de que se aprobaran 20 artículos destinados a regular los objetivos y criterios a los que quedaría sometido el Gobierno para regular el régimen salarial y prestacional de los empleados públicos de la Rama Ejecutiva Nacional, el Congreso, la Rama Judicial, el Ministerio Público, el Consejo Nacional Electoral, la Registraduría Nacional del Estado Civil, la Contraloría General de República y los miembros de la Fuerza Pública. 
El proyecto fue entregado para su sustanciación a la Comisión Primera en cabeza del entonces Senador del partido conservador Gabriel Melo Guevara. Comisión donde curso el primer debate los días 18 y 19 de febrero de 1992 y segundo debate los días 27 de febrero y 10 de marzo del mismo año.

Respecto de la Rama Judicial, tema que nos importa en razón a que como se dijo anteriormente, la Fiscalía hace parte de ésta, se consideró que: "se debía ordenar los reajustes eliminando la descompensación en las escalas de remuneración."

Terminados los dos debates, el proyecto fue entregado a la Cámara de Representantes, y se le identifico como Proyecto de ley 23 de 1991. El coordinador de ponentes fue el Exrepresentante Cesar Pérez García del partido liberal; y, cuyos ponentes fueron los Exrepresentantes Roberto Camacho Weberberg del partido conservador y Francisco José Jattin; Mario Uribe Escobar; Rodrigo Villalba y Juan Carlos Vives Menotti del partido liberal.

El primer debate fue realizado el 6 de abril de 1992, y el segundo tuvo ocasión el 22 de abril del mismo año. En el libro Historia de las leyes: legislatura 1991-1992, Tomo III, se encuentran los siguientes antecedentes:

En cumplimiento del artículo 21 transitorio se pretende que quede regulada la obligatoriedad del estado para modificar el régimen salarial de los servidores públicos por periodos anuales, con base en los índices variables 
del costo de vida. Esto incrementa igualmente los demás beneficios y elementos complementarios del salario, así como también los gastos de representación, las bonificaciones, primas, y demás incentivos que se otorguen.

Al proyecto que venía del Senado, decidieron realizarle un pliego de modificaciones que, entre otras, consistió en la creación del artículo 14. La motivación dice lo siguiente:

En aras de la equidad y con el propósito de crear un equilibrio dentro de la rama judicial acogiendo el espíritu de diversas jerarquías se presenta un nuevo artículo que cobija tales prestaciones en su conjunto, obviamente, tomándose en cuenta el factor de los recursos presupuestales.

"Artículo 14. El Gobierno Nacional establecerá una prima sin carácter salarial para los magistrados de todo orden de los tribunales judiciales incluidos los de la justicia penal militar, agentes del ministerio público delegados ante la rama judicial y para los jueces de la República, excepto los que opten por la escala de salarios de la Fiscalía General de la Nación, dentro de los plazos y términos fijados por el mismo con sujeción al numeral 14 del artículo 189 de la Constitución y lo preceptuado en el artículo 280 de la Constitución Nacional. 
Parágrafo 1ํ. En el mismo sentido revisará el sistema de remuneración de funcionarios y empleados de la rama judicial sobre la base de su nivelación o reclasificación, atendiendo criterios de equidad. "

En el transcurso del debate del 6 de abril, los Exrepresentantes Ramiro Lucio, Roberto Camacho, Guido Echeverri y Cesar Pérez presentaron una propuesta modificativa, la que fue aprobada, así:

"El Gobierno Nacional establecerá una prima no inferior al 30\% ni superior al 60\% del salario básico, sin carácter salarial, para los magistrados de todo orden de los tribunales judiciales incluidos los de la justicia penal militar, agentes del ministerio público delegados ante la rama judicial y para los jueces de la República, excepto los que opten por la escala de salarios de la Fiscalía General de la Nación, con efectos a partir del 10. de enero de 1993. Parágrafo: Así mismo revisará el sistema de remuneración de funcionarios y empleados de la rama judicial cobre la base de la nivelación o reclasificación, atendiendo criterios de equidad"

El texto definitivo en la Cámara se originó los días 28 y 29 de abril de 1992, y en el Senado el 5 de mayo del mismo año. La norma así aprobada fue publicada en el Diario Oficial No. 40451 de 18 de mayo de 1992. Texto legal del cual es pertinente sustraer los siguientes artículos: 
ARTíCULO 10. El Gobierno Nacional, con sujeción a las normas, criterios y objetivos contenidos en esta Ley, fijará el régimen salarial y prestacional de:

a) Los empleados públicos de la Rama Ejecutiva Nacional, cualquiera que sea su sector, denominación o régimen jurídico;

b) Los empleados del Congreso Nacional, la Rama Judicial, el Ministerio Público, la Fiscalía General de la Nación, la Organización Electoral y la Contraloría General de la República;

c) Los miembros del Congreso Nacional, y

d) Los miembros de la Fuerza Pública.

ARTíCULO 20. Para la fijación del régimen salarial y prestacional de los servidores enumerados en el artículo anterior, el Gobierno Nacional tendrá en cuenta los siguientes objetivos y criterios:

a) El respeto a los derechos adquiridos de los servidores del Estado tanto del régimen general, como de los regímenes especiales. En ningún caso se podrán desmejorar sus salarios y prestaciones sociales; [...]

ARTíCULO 4o. Con base en los criterios y objetivos contenidos en el artículo 2o. el Gobierno Nacional, dentro de los primeros diez días del mes de enero de cada año, modificará el sistema salarial correspondiente a los empleados enumerados en el artículo 1o literal a), b) y d), aumentando sus remuneraciones. [...] 
ARTí́CULO 10. Todo régimen salarial o prestacional que se establezca contraviniendo las disposiciones contenidas en la presente Ley o en los decretos que dicte el Gobierno Nacional en desarrollo de la misma, carecerá de todo efecto y no creará derechos adquiridos.

ARTí́culO 11. El Gobierno Nacional, dentro de los diez (10) días siguientes a la sanción de la presente Ley, en ejercicio de las autorizaciones previstas en el artículo 4o., hará los aumentos respectivos con efectos a partir del primero (10.) de enero de 1992.

ARTÍ́CULO 14. El Gobierno Nacional establecerá una prima no inferior al $30 \%$ ni superior al $60 \%$ del salario básico, sin carácter salarial para los Magistrados de todo orden de los Tribunales Superiores de Distrito Judicial y Contencioso Administrativo, Agentes del Ministerio Público delegados ante la Rama Judicial y para los Jueces de la República, incluidos los Magistrados y Fiscales del Tribunal Superior Militar, Auditores de Guerra y Jueces de Instrucción Penal Militar, excepto los que opten por la escala de salarios de la Fiscalía General de la Nación, con efectos a partir del primero (10.) de enero de 1993.

Igualmente tendrán derecho a la prima de que trata el presente artículo, los delegados departamentales del Registrador Nacional del Estado Civil, los 
Registradores del Distrito Capital y los niveles Directivo y Asesor de la Registraduría Nacional del Estado Civil.

PARÁGRAFO. Dentro del mismo término revisará el sistema de remuneración de funcionarios y empleados de la Rama Judicial sobre la base de la nivelación o reclasificación atendiendo criterios de equidad.

El Presidente de la República expidió entonces el Decreto 900 de 1992, fijando la escala de remuneración para los empleos de la Fiscalía General de la Nación, con efectos desde el 1 de enero de 1992, modificando con ello, la remuneración prevista en el Decreto 2699 de 30 de noviembre de 1991. Esta, norma según se desprende del contenido de la ley marco, intentó dar cumplimiento a lo que se dispuso en el artículo11 que se transcribió anteriormente, dando alcance también a lo dispuesto en el artículo 4 ibídem.

Con posterioridad, dando alcance a lo dispuesto en el artículo 14 de la Ley 4 de 1992, sobre el cual se ha venido haciendo referencia, el Presidente expidió el régimen salarial y prestacional para los servidores públicos de la Fiscalía General de la Nación, mediante el Decreto 53 de 7 de enero de 1993, precisando lo siguiente: 
ARTICULO 10. El régimen salarial y prestacional establecido en el presente decreto será de obligatorio cumplimiento para quienes se vinculen al servicio con posterioridad a la vigencia del mismo [...]

ARTICULO 20. Los servidores públicos vinculados a la Fiscalía General de la Nación podrán optar por una sola vez antes del 28 de febrero de 1993 por el régimen salarial y prestacional establecido en el presente decreto. Los servidores públicos que no opten por el régimen aquí establecido continuarán rigiéndose por lo dispuesto en las normas legales vigentes a la fecha.

ARTICULO 6o. El treinta por ciento (30\%) del salario básico mensual de los siguientes servidores públicos se considera como prima especial de servicios sin carácter salarial.

Jefe Unidad de Fiscalía ante Tribunal Nacional

Jefe Unidad de Fiscalía ante Tribunal de Distrito

Fiscal ante Tribunal Nacional

Jefe Unidad Regional de Fiscalía

Fiscal ante Tribunal de Distrito

Fiscal Regional

Jefe Unidad Seccional de Fiscalía

Fiscal Seccional

Secretario General 


\section{Directores Nacionales}

Directores Regionales

Directores Seccionales

Jefes de Oficina

Jefes de División

ARTICULO 18. El presente Decreto rige a partir de la fecha de su publicación, modifica en lo pertinente las disposiciones vigentes y surte efectos fiscales a partir del 10. de enero de 1993.

Es pertinente resaltar, que a partir de la expedición de esta norma, la Fiscalía General de la Nación, mantendría tres regímenes salariales distintos: 1- el que se les venía cancelando a todas aquellas personas que trabajaban en la Rama Judicial y que fueron trasladados a la entidad y no quisieron acogerse, antes del 30 de mayo de 1992, al previsto en el artículo 54 del Decreto 2699 de 1991; 2- el previsto por el Decreto 2699 de 1991 que le resulta aplicable a los que se vincularon a partir de la expedición del mismo, o los que decidieron acogerse antes del 30 de mayo de 1992; 3- el previsto por el Decreto 53 de 1993, aplicable a las personas que se vincularan a la entidad a partir de su vigencia, y para aquellas que si bien estaban en alguno de los anteriores, decidieron acogerse con anterioridad al 28 de febrero de 1993. 
Dando cumplimiento al artículo 4 de la ley 4 de 1992, el Gobierno Nacional debe todos los años expedir el aumento salarial. En lo que refiere a la pertinencia para el desarrollo del tópico de esta disertación, interesan los que desarrollaron el Decreto 53 de 1993, es decir, los Decretos 108 de 1994; 49 de 1995; 108 de 1996; 52 de 1997; 50 de 1998; 38 de 1999; 2743 de 2000; 2729 de 2001; y 685 de 2002. Los Decretos enunciados, modifican anualmente el régimen salarial y prestacional establecido en el decreto 53 de 1993, y en lo pertinente mantuvieron vigente el artículo 6.

El Consejo de Estado en acciones de nulidad conoció sobre las normas enunciadas y anuló el artículo al que se hace referencia, mediante las sentencias: 197-99 de 4 de febrero de 2002, Consejero Ponente: Nicolás Pájaro Peñaranda; 712-01 de 15 de abril de 2004, Consejero Ponente: Nicolás Pájaro Peñaranda; 3531-02 de 15 de julio de 2004, Consejera Ponente: Ana Margarita Olaya Forero; 4419-01 de 25 de noviembre de 2004, Consejera Ponente: Ana Margarita Olaya Forero; 17021 de 3 de marzo de 2005, Consejera Ponente: Ana Margarita Olaya Forero; 478-03 de 3 de septiembre de 2007, Consejero Ponente: Alejandro Ordoñez Maldonado.

Ahora bien, por el limite de extensión de esta disertación, no se presenta la sinopsis de ninguna de las sentencias referidas, pero, el siguiente aparte corresponde al análisis de la primera y la última de las enunciadas. 


\section{Análisis jurisprudencial del tópico}

Para realizar un adecuado análisis de las sentencias precitadas, se intentó establecer en la segunda unidad, algunos conceptos sobre la competencia de la administración, la forma en que se realiza el control de los actos administrativos y el efecto de las sentencias de nulidad, así como, en la tercera unidad, se narraron los hechos históricos que originaron las facultades del Presidente de la República para expedir los decretos que fueron anulados: en razón a ello, en la presente unidad se juzgara la veracidad de los argumentos que condujeron a la anulación.

En la sentencia 197-99 de 14 de febrero de 2002, la Corporación estableció que en virtud del artículo 14 de la ley 4 de 1992, el Gobierno Nacional estaba facultado para crear la prima en favor de los empleados que allí se enlistan, pero no para los funcionarios que optaron por la escala de salarios, establecida para la Fiscalía General de la Nación con efectos a partir del 1 de enero de 1993, los cuales en su entender, no son otros que los servidores a los que hace referencia el artículo 2 del Decreto 53 de 1993.

El argumento enunciado comprende tres hipótesis: primero, entiende que el Gobierno Nacional no estaba facultado para crear la prima de los funcionarios que optaron por la escala de salarios, establecida para la Fiscalía General de la Nación; segundo, que de conformidad con la redacción del artículo 14 de la ley 4 de 1992, la excepción hace referencia a los que optaron por el régimen que se 
aplicaría a partir del 1 de enero de 1993; tercero, que la excepción, hace referencia a los servidores públicos de que trata el artículo 2 del Decreto 53 de 1993.

Sin embargo, la primera hipótesis va en contraposición directa del artículo 1de la ley 4 de 1992, porque allí se estableció que el Gobierno Nacional puede fijar el régimen salarial y prestacional de los empleados públicos de la Fiscalía General de la Nación.

Respecto de la segunda hipótesis, existen dos razones que impiden realizar en el artículo dicha inferencia: la primera, es porque una vez que realiza la excepción de la Fiscalía General de la Nación, el texto presenta una coma que permite inducir que se habla de lo que viene haciendo referencia con anterioridad, en ese sentido, debe entenderse que la norma está diciendo que el Gobierno Nacional establecerá una prima con efectos a partir del 1 de enero de 1993, para los sujetos allí enunciados; Y, la segunda razón, consiste en que, en realidad el señalar dicha fecha obedece a una causa distinta, cual es qué, en el artículo 11 de la ley 4 de 1992, se estableció la puesta en marcha de los aumentos salaniales para el año 1992.

En cuanto a la tercera de las hipótesis, debe concluirse que también es falsa, por lo siguiente: el artículo 14 de la ley 4 de 1992 apareció, el 6 de abril de 1992, fecha en la cual aún no se había expedido el Decreto 53 de 1993, además, porque de un lado, la hipótesis que dice "excepto los que opten por la escala de salarios de la 
Fiscalía General de la Nación", el único sentido que puede tener es el de excluir a las personas que todavía tenían la opción de elegir el régimen salarial previsto en el artículo 54 del Decreto 2699 de 1991, en tanto que dicha opción podía ser ejercida hasta el 30 de mayo de 1992, de conformidad con el artículo 64 ibídem, y de otro lado, la intención original que creó la prima era la de crear un equilibrio dentro de la Rama Judicial, estructura donde está inmersa la Fiscalía General de la Nación y a la cual ya se le había creado un nuevo régimen salarial y prestacional adecuado a la Constitución de 1991.

Debe concluirse además, que el Gobierno Nacional, si podía establecer la prima de que trataba el artículo 7 del Decreto 38 de 1999, porque la exclusión hacía referencia a los servidores públicos que aceptaran el régimen salarial y prestacional del artículo 54 del Decreto 2699 de 1991. Aunado a lo anterior, porque el Gobierno Nacional, debía cumplir las órdenes, previstas en el artículo 1 de la Ley 4 de 1992, donde se le impuso que debía fijar el régimen salarial de la Fiscalía General de la Nación, pero, respetando los derechos adquiridos, artículo 2 literal a), facultad que además también le fue entregada por el parágrafo del artículo 14, y hechos por los cuales, en el momento oportuno se precisó que en dicha entidad a partir de la expedición del Decreto 53 de 1993, se mantenían 3 regímenes salariales: 1 - el que se les venía cancelando a todas aquellas personas que trabajaban en la Rama Judicial y que fueron trasladados a la entidad y que no quisieron acogerse, antes del 30 de mayo de 1992, al previsto en el artículo 54 del Decreto 2699 de 1991; 2- el previsto por el Decreto 2699 de 1991 que le resulta 
aplicable a los que se vincularon a partir de la expedición del mismo, o los que decidieron acogerse antes del 30 de mayo de 1992; 3- el previsto por el Decreto 53 de 1993, aplicable a las personas que se vincularan a la entidad a partir de su vigencia, y para aquellas que si bien estaban en alguno de los anteriores, decidieron acogerse con anterioridad al 28 de febrero de 1993.

Incluso, véase que otro de los argumentos limitativos a la facultad del Gobierno Nacional, fue el de establecer, qué lo dispuesto el parágrafo del artículo 14 de la Ley 4 de 1992, para revisar el sistema de remuneración de los funcionarios y empleados de la Rama Judicial sobre la base de la nivelación o reclasificación, atendiendo criterios de equidad, no podía referirse a la Fiscalía General de la Nación, porque "al aceptar este planteamiento se estaría admitiendo que el legislador, que consagró en forma expresa en el inciso primero de ese artículo la referida excepción, en el parágrafo del mismo", argumento que no resulta valido, porque como se mostró con anterioridad, la exclusión fue de algunos servidores de la entidad, y no la de la totalidad.

Desde el punto de vista, de los argumentos, presentados por el actor, vale decir en consecuencia que: la causal de nulidad entorno a la incompetencia, no era cierta; sin embargo, éste formuló otras dos causales que deben ser puestas en consideración, la primera hace referencia a la violación de normas superiores, la que hizo consistir en que se vulneran los artículos 13 y 53 de la Constitución Política, ya que la norma colocaba, en su criterio, a unos funcionarios de la 
Fiscalía General de la Nación, en una posición discriminatoria y desventajosa frente a otros, a pesar de pertenecer a la misma institución, y, el que hace referencia a la desviación de poder, en tanto que el Gobierno se alejó de los fines de la norma, ya que aparentó crear una prima, cuando en realidad despojó de efectos salariales a una parte de la remuneración.

El artículo 13 hace referencia, a la igualdad de todas las personas ante la ley, de forma que estas deben recibir la misma protección y trato de las autoridades, al respecto debe decirse que la sola enunciación del derecho hace insuficiente su valoración jurídica, más cuando se ha dicho por la Corte Constitucional, como puede leerse en la sentencia C-475 de 10 de junio de 2003, Magistrado Ponente: Jaime Córdoba Triviño, que la regulación diferenciada es válida cuando la diversidad de trato tiene fundamento objetivo y razonable, de acuerdo a la finalidad perseguida en la norma. Ahora bien, en lo que refiere al artículo 53 de la Constitución, este prevé las condiciones mínimas de los derechos laborales, entre los que se encuentran la irrenunciabilidad a los beneficios mínimos establecidos en la ley y la remuneración mínima vital y móvil, sin embargo se presenta una situación similar a la anterior, en el sentido de que al ser la Jurisdicción Contencioso Administrativa rogada, el juez no puede sobreentender lo que el demandante desea expresar.

Es cierto que en gracia de discusión, puede entenderse que dichos derechos si fueron vulnerados con lo dispuesto en el artículo 7, pero era menester, que se 
hiciera una concatenación lógica de la desigualdad laboral que se originó entre estos servidores públicos, de forma que primara el principio: "a trabajo igual remuneración igual".

En cuanto a la presunta desviación de poder, dicho argumento, puede tener dos valoraciones distintas, esto por cuanto el artículo 14 de la ley 4 de 1992, puede dar a entender dos normas jurídicas disimiles, la primera posición la expresa la Fiscalía General de la Nación cuando indica que allí se dispuso que el Gobierno establecería una prima no inferior al $30 \%$ ni superior al $60 \%$ sin carácter salarial, haciendo referencia al sueldo básico y no a una suma adicional, indicando con ello que dicho valor está contenido en el sueldo básico como parte integrante del mismo y no como excedente, y, la segunda posición consiste en establecer que cuando el legislador dispuso la creación de la prima, esta debía consistir en una sobre remuneración del salario.

En este punto, el propio Consejo de Estado, ha manejado las dos nociones, aunque actualmente se prefiere la segunda; al respecto pueden ser vistas las sentencias 121-03 de 9 de marzo de 2006, Consejero Ponente: Alejandro Ordoñez Maldonado y 1831-07 de 2 de abril de 2009, Consejero Ponente: Gustavo Eduardo Gómez Aranguren.

Pese a ello, resulta pertinente realizar 2 precisiones metodológicas, por un lado la identificación de la causal de desviación de poder, no resulta valida en tanto que 
esta se produce, como se estableció en la segunda unidad, cuando se emplea una facultad otorgada por la ley con un fin distinto del que la ley quería al otorgarla, en este caso, la creación de un régimen salarial y prestacional para la Fiscalía General de la Nación, por el contrario, la causal a invocar, debió consistir en la falta de motivos o error en los motivos, ya que son estos los que, siguiendo a Berrocal (2009), "vienen a consistir en el soporte factico y jurídico del sentido y alcance de la declaración o contenido del acto administrativo", Por otro lado, tal como se precisó en la tercera parte, el proyecto de ley tenía la intención de incrementar los beneficios y elementos complementarios del salario, y además, siendo que, al momento de realizársele el pliego de modificaciones, dentro de las que estaba la creación del artículo 14, se puede observar en la redacción primigenia que la obligación del Gobierno Nacional consistía en la creación de una prima sin carácter salarial.

Lo anterior, implica forzosamente, que dicho argumento tampoco tenía la entereza jurídica para desvirtuar la presunción de legalidad del artículo 7 del Decreto 38 de 1999, en tanto que el argumento válido para tal efecto, jamás fue sustentado.

Efectivamente, el que el Gobierno se alejara de los motivos de la norma, ya que aparentó crear una prima, cuando en realidad, despojó de efectos salariales a una parte de la remuneración, hubiera sido suficiente para anularla. 
Ahora bien, respecto de esta providencia cabe agregar, como ya se había establecido, que la sentencia de nulidad actúa retroactivamente, es decir que tiene efectos ex tunc, por lo que una vez declarada la nulidad, sus efectos se retrotraen a la fecha del acto anulado como si este nunca hubiese existido, de forma que al eliminarlo, le correspondía a la administración determinar las consecuencias, de acuerdo con la realidad práctica, es decir, sustrayendo el $30 \%$ sobre las remuneraciones. En este entendido, si bien no existe dentro de la sentencia un criterio expreso que lleve a entender, porque se regularon los efectos jurídicos de la nulidad, previendo que la anulación de la prima especial, no implicaba la reducción salarial; dicha situación, se sobreentiende que en el fondo tiene como causa el intentar proteger a los servidores públicos frente a una inminente disminución salarial, no obstante ello, siendo que de conformidad con el entendimiento de los lineamientos generales de la acción de nulidad, el Consejo de Estado ha establecido que esta tiene como única finalidad, la de velar por la integridad y coherencia del ordenamiento jurídico, es decir, busca restablecer la legalidad del mismo, y el contenido de la sentencia se limita a declarar la legalidad o ilegalidad del acto, tal situación no debió ocurrir.

Desde un punto de vista netamente jurídico, efectivamente dicha actuación no debió darse, porque el efecto de la declaración de nulidad, si bien en principio implicaba la desaparición del 30\% de la asignación salarial, los servidores que la habían recibido no tendrían que devolver dichos recursos, en virtud del inciso final del numeral 2 del artículo 136 del Código Contencioso Administrativo, y, por otra 
parte, podrían haber hecho uso de otro tipo de acciones para obtener la remuneración no cancelada, un ejemplo: sería el inicio de una acción de grupo.

Siendo que el ordenamiento jurídico prevé otros mecanismos de defensa, el haber realizado declaraciones sobre los efectos o consecuencias de la declaración de nulidad, desborda las fronteras de la capacidad del juez, más cuando sobre esta se realizarían como lo resume la sentencia 478-03 de 13 de septiembre de 2007, Consejero Ponente: Alejandro Ordoñez Maldonado, cambios en sentencias posteriores, que a la postre implican hoy en día desigualdades frente a la forma de fallo respecto de las acciones de nulidad y restablecimiento del derecho que cursaron y cursan hoy en día con motivo de estos pronunciamientos. Para el efecto, pueden ser revisadas entre otras, las siguientes: 17918 de 24 de mayo de 2001, Consejero Ponente: Nicolás Pájaro Peñaranda; 3146-00 de 12 de julio de 2001, Consejero Ponente: Nicolás Pájaro Peñaranda; 3094-03 de 3 de junio de 2004, Consejero Ponente: Nicolás Pájaro Peñaranda; 2077-03 de 1 de septiembre de 2005, Consejero Ponente: Jesús María Lemos Bustamante; 2451-2002 de 28 de septiembre de 2006, Consejero Ponente: Alejandro Ordóñez Maldonado (E); 0451-04 de 22 de febrero de 2007, Consejera Ponente: Bertha Lucía Ramírez de Páez; 3163-07 de 19 de junio de 2008, Consejero Ponente: Jesús María Lemos Bustamante; 1295--07 de 30 de octubre de 2008, Consejero Ponente: Gustavo Eduardo Gómez Aranguren; 2354-07 de 1 de octubre de dos 2009, Consejero Ponente: Gerardo Arenas Monsalve; 0115-08 de 8 de abril de 2010, Consejero ponente: Víctor Hernando Alvarado Ardila. 
En lo que atañe a la sentencia 478-03 de 13 de septiembre de 2007, Consejero Ponente: Alejandro Ordoñez Maldonado, es incuestionable que la misma presenta en algunos apartes, argumentos como los que se han establecido en los párrafos anteriores, véase que en su tenor literal dice, "al paso que las disposiciones aquí impugnadas, no establecen propiamente tal prima sino que señalan que un porcentaje del sueldo básico (30\%), constituye prima especial de servicios sin carácter salarial."

Sin embargo en otros partes, por el contrario establece ideas que llevan a la confusión: "concluye que la disposición enunciada en el artículo 14 de la ley 4 de 1992 se refería a los servidores públicos de la Fiscalía General de la Nación que se vincularon por primera vez, o que siendo de aquellos que debían incorporarse, se acogieron a la escala de salarios prevista en el artículo 54 del Decreto 2699 de 1991.", cabe aquí preguntar entonces a qué momento de vinculación se refiere; y, "El Presidente de la República mediante los Decreto 53 de 1993, expidió normas sobre el régimen salarial y prestacional para los servidores públicos de la Fiscalía General de la Nación, de obligatorio cumplimiento para quienes se vinculen al servicio con posterioridad a la vigencia del mismo. A ellos se aplicaba la escala salarial que había sido establecida en el artículo 54 del Decreto 2699 de 1991." Situación que no se acomoda a la realidad, en el sentido de que el Decreto 2699 de 1991, era un régimen totalmente distinto, que tuvo que ser mantenido en razón a que así lo dispuso el artículo 2 literal a) de la Ley 4 de 1992; como lo establece el salvamento de voto de la sentencia 197-99 de 14 de febrero de 2002, este tuvo 
su propio desarrollo, entre otros, con los Decretos 900 de 1992, 52 de 1993, 84 de 1994, 50 de 1995, 109 de 1996, 50 de 1997, 52 de 1998, 41 de 1999, 2744 de 2000, mientras que el Decreto 53 como régimen salarial distinto, se desarrolló con los Decretos 108 de 1994; 49 de 1995; 108 de 1996; 52 de 1997; 50 de 1998; 38 de 1999; 2743 de 2000; 2729 de 2001; y 685 de 2002.

Estos hechos, conducen a entender que no es jurídicamente apropiado afirmar que: "es evidente que las disposiciones demandadas al señalar que "El treinta por ciento $(30 \%)$ del salario básico mensual de los siguientes servidores públicos se considera como prima especial de servicios sin carácter salarial”, contrarió las previsiones del artículo 14 de la Ley $4^{\mathrm{a}}$ de 1992 , pues como se ha venido haciendo claridad, estos, precisamente, eran los que la citada ley señalaba como no destinatarios de la misma."; obsérvese incluso que la sentencia en comento, vuelve a incurrir en el error de interpretación al que se hizo alusión en párrafos anteriores al establecer en uno de sus apartes que la excepción prevista por el artículo 14 de la Ley 4 de 1992 hacía referencia a "los que opten por la escala de salarios de la Fiscalía General de la Nación con efectos fiscales a partir del 1ํ de enero de 1993."

Finalmente, en cuanto a lo que tiene que ver con las consideraciones, la sentencia reinterpreta la modulación de los efectos jurídicos de la nulidad, estableciendo que como consecuencia de la declaración de nulidad de las disposiciones, no se les reducen sus ingresos mensuales, en razón a que tales normas no habían 
establecido un "sobresueldo", fenómeno al que debe realizársele la misma critica hecha a la sentencia 197-99 de 14 de febrero de 2002.

Ahora bien, en lo que tiene que ver con las razones jurídicas expuestas en la demanda, se observa que si bien el argumento de conexidad entre el primer fallo frente a la norma allí demandada y las accionadas en esta oportunidad, es legítimo, tal como lo expone también el Ministerio Público en su intervención, lo cierto es que intrínsecamente no es válido, en tanto que dicha nulidad no debió haber sido proferida.

La accionante, también expuso que las normas por ella atacadas infringen el artículo 14 de la Ley 4 de 1992, como quiera que establecieron un treinta por ciento del salario básico mensual como prima especial de servicios, para algunos de los servidores de la Fiscalía General de la Nación, cuando según su entender, dicha norma los había exceptuado expresamente, al respecto valga reafirmar que dicha excepción sólo podía hacer referencia a los servidores que mantenían el régimen salarial y prestacional previsto en el artículo 54 del Decreto 2699 de 1991, por lo que en sí la proposición es falsa.

Los argumentos del párrafo anterior son igualmente válidos para la alegada desviación de poder, por desbordamiento de su potestad reglamentaria, pues esta la soporto en que no podía crearse la prima para los servidores públicos de la Fiscalía General de la Nación. 
Las normas en que fundamento la vulneración del ordenamiento jurídico, son: artículo 14 de la Ley 4 de 1992; artículos 54 y 64 del Decreto 2699 de 1991; y artículo 150, numeral 19, literal e) de la Constitución Política, no fueron infringidas, y por tanto la nulidad de los artículos no debió ser declarada, por cuanto se repite que la Jurisdicción Contencioso Administrativa tiene la característica de ser rogada.

Respecto de las consideraciones expuestas por el Ministerio Hacienda y Crédito Público, en el sentido de que no era procedente iniciar un juicio sobre los decretos 2743 de 2000 y 2729 de 2001, en virtud de que estas normas ya no existen en el ordenamiento jurídico y fueron derogadas, vale la pena traer a colación, que la Jurisdicción Contencioso Administrativa, ha expuesto en múltiples providencias, que siempre que el acto jurídico de que se trate haya producido consecuencias jurídicas, puede ser analizado, por cuanto las mismas podrían desaparecer si se anula la norma que le sirve de causa, para el efecto se pueden observar, las sentencias Al-042 de 12 de julio de 1998, y Al-038 de 18 de enero de 2000, Consejero Ponente: Manuel Santiago Urueta Ayola.

\section{Conclusiones}

Como consecuencia de lo hasta aquí expuesto, se debe concluir que si bien las normas debieron ser anuladas por error en los motivos, lo cierto es que hubiera 
sido necesario el ejercicio de una nueva acción de nulidad, sin que sea válido afirmar aquí, que en últimas siendo que la norma es injusta a pesar de que los fallos no tienen una argumentación valida se cumplió con la finalidad del ordenamiento jurídico, pues, como se dijo anteriormente a la postre dicha situación implican hoy en día desigualdades frente a la forma de fallo respecto de las acciones de nulidad y restablecimiento del derecho que cursaron y cursan hoy en día, y además por cuanto los verdaderos efectos de la eliminación de la prima, no hubieran tenido nefastas consecuencias porque el ordenamiento jurídico prevé otras formas para salvaguardar el derecho vulnerado.

Además, ello debió ser así, pues como se puede observar de forma sólo ejemplarizante, se puede leer en la sentencia 1998-90201 de 11 de octubre de 2006, Consejero Ponente: Rafael E. Ostau de Lafont Pianeta que:

[S]i la decisión jurisdiccional es negativa, es decir si el acto demandado continúa vigente, la cosa juzgada se predica, únicamente de las causales de nulidad alegadas y del contenido del petitum que no prosperó. En consecuencia la norma puede ser demandada por otra causa y puede prosperar la pretensión [...]"

Ya que sólo se consideran admisibles aquellas decisiones fundamentadas en juicios, criterios o parámetros claramente identificables que puedan ser examinados desde una perspectiva externa a la decisión misma y que la única 
justificación posible yace en el cumplimiento de la normatividad, es decir, tanto en lo procedimental como en lo sustancial, lo que implica también el logro de los fines previstos por la Constitución, es necesario que se dé una corrección.

A título ilustrativo, se sugeriría que siendo que la mayoría de los argumentos expuestos en las sentencias declaratorias de la nulidad, consisten en meros Obiter Dictum, podría pensarse que en las sentencias que ha futuro se produzcan no debieran hacer mención alguna de los efectos de las nulidades realizadas, por cuanto si se preguntase ¿Qué es lo que se persigue con la declaración de nulidad?, la respuesta lógica es que se declare legal o ilegal el acto jurídico acusado, y siendo que sí el acto es ilegal la consecuencia es que no existió, entonces se tiene que la razón de la decisión, Ratio Decidendi, es su inconformidad con el ordenamiento jurídico y no los efectos de los fallos. Sobre este tema se puede leer la sentencia del consejo de estado 2001-0163 de 19 de febrero de 2002, Consejero Ponente: Ricardo Hoyos Duque.

Podrá irse en contra de la idea expuesta, argumentando, que debido a la seguridad jurídica y a los efectos de la cosa juzgada, es imposible volver a abrir el debate; incluso, se podrá decir también que siendo que la competencia del juez termina con la providencia, y luego este no puede volver a asumirla, las cosas han quedado ya plenamente establecidas. 
Pero es que debe recordarse aquí: primero: que de conformidad con el artículo 90 de la Constitución y, en especial, los artículos 65 y s.s. de la Ley 270 de 1996 el Estado responde por los daños antijurídicos que le sean imputables por la acción o la omisión de sus agentes judiciales; en ese sentido es muy significativo lo dispuesto en el artículo 66 ibídem donde se establece que el error jurisdiccional: "Es aquel cometido por una autoridad investida de facultad jurisdiccional, en su carácter de tal, en el curso de un proceso, materializado a través de una providencia contraria a la ley.". Y siendo, que no puede ser jurídico lo realizado por fuera de los precisos términos de la ley; como segundo punto, que tratándose de la ciencia jurídica y resaltando con énfasis, las teorías de la aceptabilidad general, debe procederse a la corrección.

Es cierto, indudablemente que la noción de la cosa juzgada: con la cual se quiere evitar que entre las mismas partes, por igual causa y sobre idéntico objeto se instaure un segundo proceso. Camacho (2006), alude a que es la necesidad de darle a la decisión proferida la calidad de definitiva y evitar así que vuelvan a plantearse en otro, lo que haría interminable la controversia. Pero es más relevante, fenómenos como el que prevé el artículo 158 del Código Contencioso Administrativo, en el sentido de que la prohibición para reproducir los actos anulados, se mantiene, si se conserva en esencia la mismas disposición, a menos que con posterioridad hayan desaparecido los fundamentos legales de esa suspensión o anulación. Inclusive, deben resaltarse razonamientos como los expuestos para el ejemplo en la sentencia 0115-08 de 8 de abril de 2010, 
Consejero ponente: Víctor Hernando Alvarado Ardila, por la cual se establece que no era jurídicamente posible aplicar la prescripción del Decreto 1848 de 1969 en razón a que "[...] En verdad, no puede esperarse que el interesado se anticipara a lo que tiempo después determinó la jurisdicción, cuando anuló las normas que excluyeron la Prima Especial como factor salarial.[...]", "[...] pues no podía anticiparse el interesado a la nulidad de las reglas que por entonces limitaban su derecho, pues mientras ellas no fueran excluidas del ordenamiento conservaban la presunción de legalidad[...]"

Marín (2007) establece que: “El derecho no tiene como única función delimitar los espacios dentro de los cuales cada quien puede buscar la satisfacción de sus particulares propósitos, sino también la de promover de manera activa el logro de determinados intereses sociales."

Esta exposición debiera llevar a pensar que es necesario extender las consecuencias reales de lo que debió haber sido el origen de la norma, por dos puntos de vista: primero: porque el artículo 53 de la Constitución no es sólo una norma enunciativa, sino regulativa (recuérdese el artículo 4 ibídem), y en ella se dispone la "[...] irrenunciabilidad a los beneficios mínimos establecidos en normas laborales [...], tal como lo fue el derecho otorgado por el legislador a recibir una prima especial entre el 30 y el $60 \%$, como una sobre remuneración y no como una sustracción al salario básico; segundo: siendo que la cosa juzgada, alude a que es la necesidad de darle a la decisión proferida la calidad de definitiva y evitar así 
que vuelvan a plantearse en otro, lo que haría interminable la controversia, lo cierto es que la especificidad del tipo de acto administrativo que aquí se analizó, conduce a pensar que es necesario ver el hecho en su completa dimensión, es decir, la controversia no era posible asumirla artículo por artículo sino el fenómeno jurídico completo, lo que implica, que (en teoría) no era dable analizar sólo la situación de cada uno de los Fiscales que demandaron en acción de nulidad y restablecimiento del derecho, fenómeno por el cual tuvieron ocurrencia las mentadas desigualdades frente a la forma de fallo, sino que de haberse declarado la nulidad por los motivos que eran, de suyo era que todos hubieran obtenido la reivindicación de su derecho de forma automática, "como si la disposición viciada jama subiera existido".

Este punto, en específico, debe explicarse así, los decretos reglamentarios especiales, son tan diferentes de otras normas jurídicas, que rompen la típica idea de cosa juzgada absoluta una vez fallada la situación jurídica, en estos casos, como la norma es idéntica y se repite año tras año, en el momento en que la jurisdicción se pronuncie sobre una cualquiera de las normas repetidas, se produce una cosa juzgada relativa, hasta que no sean resueltos todos los casos que sobre el mismo contenido jurídico se puedan presentar. A esto se hace referencia en el párrafo anterior, cuando se dice que es necesario ver el hecho en su completa dimensión. 
La ciencia jurídica, debe tender a esta reivindicación, de lo contrario fenómenos como el estudiado en esta disertación quedaran como la mera constatación de lo que debió haber sido, implicando con ello, un enorme riesgo, pues ahora que el nuevo código contencioso administrativo ley 1437 de 2011, empiece a regir, las situaciones enunciadas pueden multiplicarse por mil en razón a que allí se dispuso la"Extensión de la jurisprudencia del Consejo de Estado a terceros por parte de las autoridades."

\section{REFERENCIAS}

Berrocal L. E., 2009. Manual del Acto Administrativo (5ª ed). Bogotá: Editorial Abc, Ediciones del Profesional

Camacho, A. (2006). Manual de Derecho Procesal (9ae ed. TI). Bogotá: Editorial Temis.

Historia de las leyes: legislatura 1991-1992, Tomo III.

Máynes, E. G. (2002). Positivismo jurídico, realismo sociológico y iusnaturalismo (4ª ed.). México: Distribuciones Fontamara S.A., 
Marín H. A. (2007). Discrecionalidad administrativa. Bogotá: Universidad Externado

Vidal J. (2004). Derecho Administrativo (12 ${ }^{\mathrm{va}}$ ed.). Bogotá: Universidad del rosario

Villamil, E. (2004). Estructura de la sentencia judicial. Bogotá: Imprenta Nacional.

Atienza, M. (1990), Para una teoría de la argumentación jurídica. [Versión electrónica]. Extraído el 12 de agosto de 2010 desde: http://enj.org/portal/biblioteca/penal/fundamentacion de recursos/27.pdf.

Garrido, M. I. (2009), la predecibilidad de las decisiones judiciales. [versión electrónica]. lus et praxis. 15,1, 55-72, Extraído el 6 de septiembre de 2010 desde http://dialnet.unirioja.es/servlet/articulo?codigo=3057349.

Mora G (2006), razón práctica y teoría del derecho: a propósito del oficio del jurista [versión electronica]. Dikaion, universidad de la sabana. 20,15, 307-322 Extraído el 10 de diciembre de 2010 desde http://dialnet.unirioja.es/servlet/fichero articulo?codigo $=2292111 \&$ orden $=0$

Sentencias del Consejo de Estado

612 IJ de 23 de julio de 1996, Consejero Ponente: Juan Alberto Polo Figueroa; 
Al- 054 y 6584 Acumulados de 31 de julio de 2003, Consejero Ponente: Gabriel E. Mendoza Martelo;

9899 de 18 de abril de 1996, Consejero Ponente Carlos Betancur Jaramillo;

IJ 030 de 4 de marzo de 2003, Consejero Ponente Manuel Santiago Urueta Ayola;

197-99 de 4 de febrero de 2002, Consejero Ponente: Nicolás Pájaro Peñaranda;

712-01 de 15 de abril de 2004, Consejero Ponente: Nicolás Pájaro Peñaranda;

3531-02 de 15 de julio de 2004, Consejera Ponente: Ana Margarita Olaya Forero;

4419-01 de 25 de noviembre de 2004, Consejera Ponente: Ana Margarita Olaya Forero;

17021 de 3 de marzo de 2005, Consejera Ponente: Ana Margarita Olaya Forero;

478-03 de 3 de septiembre de 2007, Consejero Ponente: Alejandro Ordoñez Maldonado;

121-03 de 9 de marzo de 2006, Consejero Ponente: Alejandro Ordoñez Maldonado; 
1831-07 de 2 de abril de 2009, Consejero Ponente: Gustavo Eduardo Gómez Aranguren;

17918 de 24 de mayo de 2001, Consejero Ponente: Nicolás Pájaro Peñaranda;

3146-00 de 12 de julio de 2001, Consejero Ponente: Nicolás Pájaro Peñaranda;

3094-03 de 3 de junio de 2004, Consejero Ponente: Nicolás Pájaro Peñaranda;

2077-03 de 1 de septiembre de 2005, Consejero Ponente: Jesús María Lemos Bustamante;

2451-2002 de 28 de septiembre de 2006, Consejero Ponente: Alejandro Ordóñez Maldonado (E);

0451-04 de 22 de febrero de 2007, Consejera Ponente: Bertha Lucía Ramírez de Páez;

3163-07 de 19 de junio de 2008, Consejero Ponente: Jesús María Lemos Bustamante;

1295--07 de 30 de octubre de 2008, Consejero Ponente: Gustavo Eduardo Gómez Aranguren; 
2354-07 de 1 de octubre de dos 2009, Consejero Ponente: Gerardo Arenas Monsalve;

0115-08 de 8 de abril de 2010, Consejero ponente: Víctor Hernando Alvarado Ardila;

2001-0163 de 19 de febrero de 2002, Consejero Ponente: Ricardo Hoyos Duque;

Al-042 de 12 de julio de 1998, , Consejero Ponente: Manuel Santiago Urueta Ayola;

Al-038 de 18 de enero de 2000, Consejero Ponente: Manuel Santiago Urueta Ayola;

1998-90201 de 11 de octubre de 2006, Consejero Ponente: Rafael E. Ostau de Lafont Pianeta

Sentencias de la Corte Constitucional:

C-089 A de 3 de marzo de 1994, Magistrado Ponente Vladimiro Naranjo Mesa;

C- 668 de 16 de agosto de 2006, Magistrado Ponente Jaime Araujo Rentería; 
C-624 de 14 de agosto de 2007, Magistrado Ponente Jaime Córdoba Triviño;

C-475 de 10 de junio de 2003, Magistrado Ponente: Jaime Córdoba Triviño 